\title{
Can the pyruvate: ferredoxin oxidoreductase (PFOR) gene be used as an additional marker to discriminate among Blastocystis strains or subtypes?
}

Patricia Alarcon-Valdes ${ }^{1}$, Guiehdani Villalobos ${ }^{2}$, Williams Arony Martinez-Flores ${ }^{3}$, Eduardo Lopez-Escamilla ${ }^{3}$, Nelly Raquel Gonzalez-Arenas ${ }^{3}$, Mirza Romero-Valdovinos ${ }^{3}$, Fernando Martinez-Hernandez ${ }^{3^{*}}$, Jonnathan Guadalupe Santillan-Benitez ${ }^{1}$ and Pablo Maravilla ${ }^{3^{*}}$

\begin{abstract}
Background: Blastocystis spp. are the most prevalent intestinal eukaryotes identified in humans, with at least 17 genetic subtypes (ST) based on genes coding for the small-subunit ribosomal RNA (18S). It has been argued that the 185 gene should not be the marker of choice to discriminate between STs of these strains because this marker exhibits high intra-genomic polymorphism. By contrast, pyruvate:ferredoxin oxidoreductase (PFOR) is a relevant enzyme involved in the core energy metabolism of many anaerobic microorganisms such as Blastocystis, which, in other protozoa, shows more polymorphisms than the 185 gene and thus may offer finer discrimination when trying to identify Blastocystis ST. Therefore, the objective of the present study was to assess the suitability of the PFOR gene as an additional marker to discriminate among Blastocystis strains or subtypes from symptomatic carrier children.
\end{abstract}

Methods: Faecal samples from 192 children with gastrointestinal symptoms from the State of Mexico were submitted for coprological study. Twenty-one of these samples were positive only for Blastocystis spp.; these samples were analysed by PCR sequencing of regions of the 185 and PFOR genes. The amplicons were purified and sequenced; afterwards, both markers were assessed for genetic diversity.

Results: The $18 \mathrm{~S}$ analysis showed the following frequencies of Blastocystis subtypes: ST3 = 43\%; ST1 = 38\%; ST2 = 14\%; and ST7 $=5 \%$. Additionally, using subtype-specific primer sets, two samples showed mixed Blastocystis ST1 and ST2 infection. For PFOR, Bayesian inference revealed the presence of three clades (I-III); two of them grouped different ST samples, and one grouped six samples of ST3 (III). Nucleotide diversity ( $\pi$ ) and haplotype polymorphism $(\theta)$ for the 185 analysis were similar for ST1 and ST2 $(\pi=\sim 0.025$ and $\theta=\sim 0.036)$; remarkably, ST3 showed almost 10-fold lower values. For PFOR, a similar trend was found: clade I and II had $\pi=\sim 0.05$ and $\theta=\sim 0.05$, whereas for clade III, the values were almost 6-fold lower.

Conclusions: Although the fragment of the PFOR gene analysed in the present study did not allow discrimination between Blastocystis STs, this marker grouped the samples in three clades with strengthened support, suggesting that PFOR may be under different selective pressures and evolutionary histories than the 185 gene. Interestingly, the ST3 sequences showed lower variability with probable purifying selection in both markers, meaning that evolutionary forces drive differential processes among Blastocystis STs.

Keywords: Blastocystis spp., Blastocystis subtypes, Genetic polymorphism, Intestinal parasites, Pyruvate:ferredoxin oxidoreductase

\footnotetext{
* Correspondence: fherxyz@yahoo.com; maravillap@yahoo.com

${ }^{3}$ Hospital General "Dr. Manuel Gea Gonzalez", Calzada de Tlalpan 4800,

Ciudad de Mexico, 14080 Ciudad de Mexico, Mexico

Full list of author information is available at the end of the article
}

(c) The Author(s). 2018 Open Access This article is distributed under the terms of the Creative Commons Attribution 4.0 International License (http://creativecommons.org/licenses/by/4.0/), which permits unrestricted use, distribution, and reproduction in any medium, provided you give appropriate credit to the original author(s) and the source, provide a link to the Creative Commons license, and indicate if changes were made. The Creative Commons Public Domain Dedication waiver (http://creativecommons.org/publicdomain/zero/1.0/) applies to the data made available in this article, unless otherwise stated. 


\section{Background}

Blastocystis spp. are the most prevalent intestinal eukaryotes identified in humans and are one of the two known stramenopiles that can infect humans [1-4]. Low host specificity and extensive morphological and genetic diversity have been documented in this genus [4, 5]. Four stages or morphotypes are presently recognized in Blastocystis: vacuolar, also named "central body", granular, amoeboid and cyst. Furthermore, 17 ribosomal lineages, known as subtypes (ST), have been described based on genotyping of the small-subunit ribosomal RNA (18S). ST1-ST9 are found in humans; however, they have also been reported in other hosts [5-8]. Some epidemiological and molecular data support a potential pathogenic role for these microorganisms [9-11]. However, the clinical relevance of Blastocystis is still controversial $[12,13]$. Previous studies suggest that due to the exceptional inter- and intra-subtype genetic variability, it is not possible to establish, without doubt, the pathogenic role of Blastocystis because pathogenesis may be subtype-dependent $[14,15]$.

Recently, some factors known as "moonlighting proteins" were shown to be capable of enhancing virulence in eukaryotic pathogens; these proteins are enzymes with key metabolic functions in glycolysis, the pentose phosphate cycle or other fundamental intracellular processes. These proteins may perform non-catalytic roles with different functions depending on their cellular localization and the concentration of substrates or additional ligands. This group of proteins includes the pyruvate:ferredoxin oxidoreductase enzyme (PFOR) [16, 17].

PFOR is a Fe-S enzyme that uses thiamine pyrophosphate (TPP) and magnesium $\left(\mathrm{Mg}^{+2}\right)$ as cofactors. It is involved in the energy metabolism of many anaerobic organisms and allows energy conservation by substrate-level phosphorylation with reversible catalysis of the oxidative decarboxylation of pyruvate to Acetyl-CoA and $\mathrm{CO}_{2}$. The resulting electrons are transferred to a low-redox potential, which depending on the physiological electron acceptor may involve hydrogen or activate molecules [18-20].

PFOR was initially identified in Clostridium acidi-urici [21], but the first description of its enzyme activity in eukaryotes was in Entamoeba histolytica [22]. It was subsequently described in other anaerobic parasites such as Trichomonas vaginalis [23], Giardia lamblia [24] and Blastocystis spp. [25]. In vivo and in vitro studies of the role of PFOR expression in parasites have suggested that it could be involved in cytoadherence, in the proliferation of trophozoites, and, under specific conditions, in the formation of subcutaneous abscesses [26]. Therefore, the purpose of this study was to assess the suitability of using the PFOR gene as an additional marker to discriminate among Blastocystis strains or subtypes from symptomatic carrier children.

\section{Methods}

Faecal samples from 192 children who attended medical consultation for gastrointestinal disorders at the Hospital para el Niño del Instituto Materno Infantil from the State of Mexico (IMIEM) between January and June 2017 were analysed by coprological methods. Faust's technique and microscopic observation were used to search for parasitic structures and to define the parasitic load per field using the $40 \times$ objective.

Approximately $50 \mathrm{mg}$ of faeces from each participant was cultured in $7 \mathrm{ml}$ of Boeck-Drbohlav modified medium at $37^{\circ} \mathrm{C}$ for 3 days [27]. The concentration of Blastocystis cells was measured in a Neubauer chamber at $0 \mathrm{~h}, 48 \mathrm{~h}$ and $72 \mathrm{~h}$. Additionally, an aliquot of up to $200 \mu \mathrm{l}$ containing Blastocystis cells was used to extract DNA using a ZR Fecal DNA MiniPrepTM kit (Zymo Research, Irvine, CA, USA) according to the manufacturer's protocol; the DNA concentration was determined by UV spectrophotometry, and DNA aliquots were stored at $-20{ }^{\circ} \mathrm{C}$ until molecular analysis.

Subtype identification was performed according to Santin et al. [28]. To establish mixed infections between Blastocystis ST1, ST2 and ST3, ST-specific primers from previous reports were used [10,11, 29-33]. To analyse the PFOR gene, specific primers for Blastocystis were designed based on available sequences in the GenBank database (ST7, XM_013038360; ST7, XM_013042447; ST4, XM_014671717; ST4, XM_014673113; ST7, XM_ 013039547; ST7, XM 013041057; ST7, XM_013038149; ST7, XM_013041791; and NandII ST1, EF512300). A suitable region of $\sim 871$ bp was chosen for amplification by the primers BlasPFOR-F: 5'-TGG CGA ACG CGA TGG GCT GCT CG-3' and BlasPFOR-R: 5'-CCA GCT GGA ACG GGT TCT CGC CC-3'.

The PCR mixture contained $25 \mathrm{pmol} / \mu \mathrm{l}$ each primer, $200 \mathrm{ng} / \mu \mathrm{l}$ genomic DNA, $2 \mathrm{mM} \mathrm{MgCl} 2,1 \times$ PCR buffer (200 mM Tris- $\mathrm{HCl}, \mathrm{pH} 8.4,500 \mathrm{mM} \mathrm{KCl}), 0.2 \mathrm{mM}$ dNTPs, $0.01 \mathrm{mg}$ of BSA and $1 \mathrm{U}$ of Taq DNA polymerase (Invitrogen, Carlsbad, CA, USA); concentration of reagents was calculated and adjusted for $25 \mu \mathrm{l}$ volume reaction.

A total of 40 cycles, each consisting of $94{ }^{\circ} \mathrm{C}$ for $30 \mathrm{~s}, 69$ ${ }^{\circ} \mathrm{C}$ for $90 \mathrm{~s}$ and $72{ }^{\circ} \mathrm{C}$ for $60 \mathrm{~s}$, was performed; an initial pre-heat step at $94{ }^{\circ} \mathrm{C}$ for $5 \mathrm{~min}$ and a final extension step at $72{ }^{\circ} \mathrm{C}$ for $7 \mathrm{~min}$ were also included. The PCR products were separated by $1.2 \%$ agarose gel electrophoresis, visualized by ethidium bromide staining $(0.5 \mu \mathrm{g} / \mathrm{ml})$ and purified with an illustra ${ }^{\mathrm{TM}} \mathrm{GFX}^{\mathrm{TM}}$ PCR DNA and Gel Band Purification kit (GE Healthcare, Little Chalfont, Buckinghamshire, UK). The purified products were sequenced in both directions at the Instituto de Biologia, Universidad Nacional Autonoma de Mexico. DNA of the Blastocystis strain ATCC-50754 (ST3) was used as a positive control. 
All sequences were subjected to BLAST searches in the GenBank database to confirm they were from Blastocystis spp. specimens. Sequences for both genes obtained in this study were aligned with those available in public databases using the Clustal W and Muscle algorithms included in MEGA software version 7.0.26 [34-36]. Phylogenetic reconstruction was conducted using a Bayesian approach with MrBayes version 3.2 [37]. The analysis was performed for 10,000,000 generations with sampling trees every 100 generations. Trees with scores lower than those at the stationary phase ('burn-in') were discarded, and trees that reached the stationary phase were collected and used to build majority consensus trees. Other sequences of $18 S$ from different Blastocystis STs and PFOR from other pathogens (such as Entamoeba spp. and Trichomonas vaginalis) were obtained from GenBank and used as references.

Genetic diversity indices for both the $18 S$ and PFOR sequences were obtained with DnaSPv6 software [38] and included nucleotide diversity ( $\pi$, the average proportion of nucleotide differences between all possible pairs of sequences in the sample) and haplotype polymorphism $(\theta$, the proportion of nucleotide sites that are expected to be polymorphic in any suitable sample from this region of the genome). These indices range in value from 0 to 1 and are used to assess polymorphisms at the DNA level, to measure variability within or between ecological populations, and to examine the genetic variability in related species or their evolutionary relationships. Additionally, to assess if our sequences were evolving randomly (neutrally) or were under a selection process, they were subjected to Tajima's D test, in which positive values indicate a decrease in population size or balancing selection, while negative values suggest expansion of the population or purifying selection [39].

\section{Results}

In the 192 samples analysed by microscopy, the following parasites were identified: Blastocystis spp. (36.5\%); Entamoeba coli (33\%); Endolimax nana (32\%); Entamoeba histolytica/E. dispar (15\%); Hymenolepis nana (10\%); and Enterobius vermicularis (5.5\%). Samples belonging to 21 children exhibited Blastocystis single infections (Table 1). In these cases, abdominal pain was the main symptom described by all patients, and the vacuolar form was observed in all samples. The clinical and demographic data, parasite load, and genotyping of both the $18 S$ and PFOR genes are summarized in Table 1.

For the 21 samples positive for Blastocystis, as well as for the commercial strain ATCC-50754, all sequences were obtained for both the $18 S$ and PFOR genes (GenBank: MH453913-MH453934 and MH507339-MH507360, respectively). In this study, the Blastocystis STs were identified as ST3 (43\%), ST1 (38\%), ST2 (14\%) and ST7 (5\%); only two samples showed mixed ST infection with ST1 and ST2.

The Bayesian phylogenetic tree built for 185 corroborated the Blastocystis ST distribution (Fig. 1). In contrast, the tree generated for PFOR grouped parasite species into different clades, and the main Blastocystis clade did not show a clear distribution of STs. In two clades (I and II), a mixture of STs was observed; in clade III, six ST3 samples plus the ATCC commercial strain were grouped (Fig. 2).

The genetic diversity indices obtained in the $18 \mathrm{~S}$ analysis showed similar values between ST1 and ST2, with $\pi=$ 0.025 and $\theta=0.036$. Recall that $\pi$ denotes the proportion of nucleotide differences between possible pairs of sequences and $\theta$ is the proportion of nucleotide sites that are expected to be polymorphic in any suitable sample from this region of the genome. Remarkably, the values for ST3 were almost 10-fold lower than other STs $(\pi=$ 0.004 and $\theta=0.005)$. In the same analysis of the PFOR gene, a similar trend was found for clades I and II $(\pi=$ 0.05 and $\theta=0.05$ ); whereas for clade III, the genetic diversity indices values were $\pi=0.008$ and $\theta=0.009$. Tajima's $\mathrm{D}$ test showed negative values for ST1-ST3 and clades I-III for both the $18 S$ and PFOR markers (Table 2).

\section{Discussion}

It has been argued that the $18 \mathrm{~S}$ rRNA gene, which is commonly used to distinguish Blastocystis STs, should not be the marker of choice for discriminating between strains within these STs [40, 41]. Poirier et al. [40] reported that although Blastocystis has a high genetic diversity, the $18 S$ rRNA gene possesses at least 17 copies that can be grouped into 6 clades. However, in ST7 comparisons with different strains, 4 of the 6 clades showed high identity within the strains compared. Markers other than the $18 S$ rRNA gene have been used to distinguish among Blastocystis strains or subtypes [40-42]. Villalobos et al. [41] compared the internal transcribed spacers (ITS) of ST1, ST2, ST3 and ST7 identified in human samples and found two variants of ST1. Poirier et al. [40] reported that a single-copy subtyping rDNA marker in the genome of mitochondria-like organelles was capable of successfully subtyping 66 isolates of Blastocystis ST1-ST10 from both humans and animals and could also detect co-infections by different isolates of the same ST. In the present study, we assessed the level of genetic diversity in an $\sim 871$ bp region of the PFOR gene of Blastocystis isolates from symptomatic carriers.

Blastocystis subtyping in samples provided by carriers from the State of Mexico has not been previously documented. We found that ST3 and ST1 were the most frequent subtypes, consistent with previous reports describing children infected with Blastocystis from other states in Mexico [41, 43]. Similarly, the values obtained 


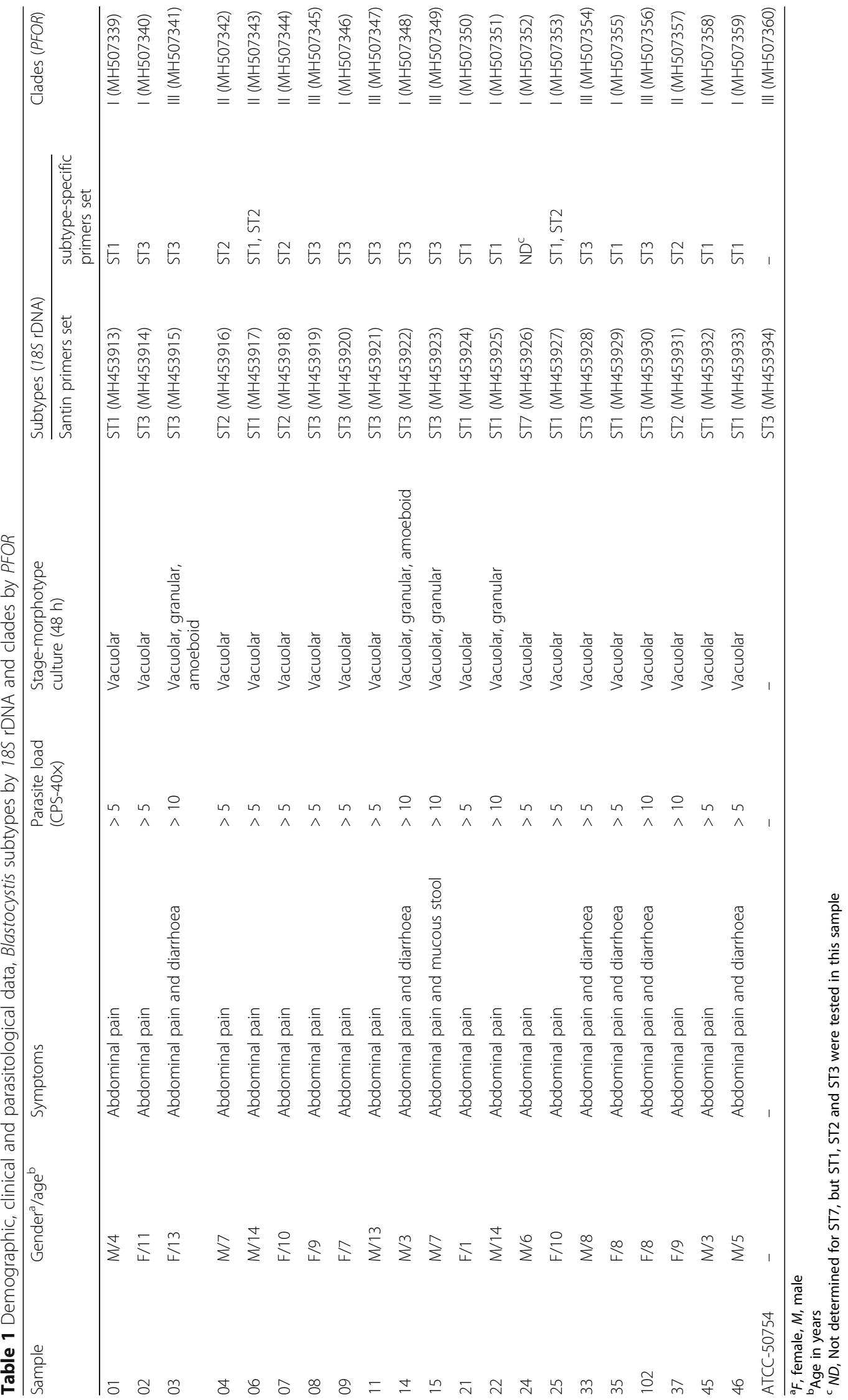




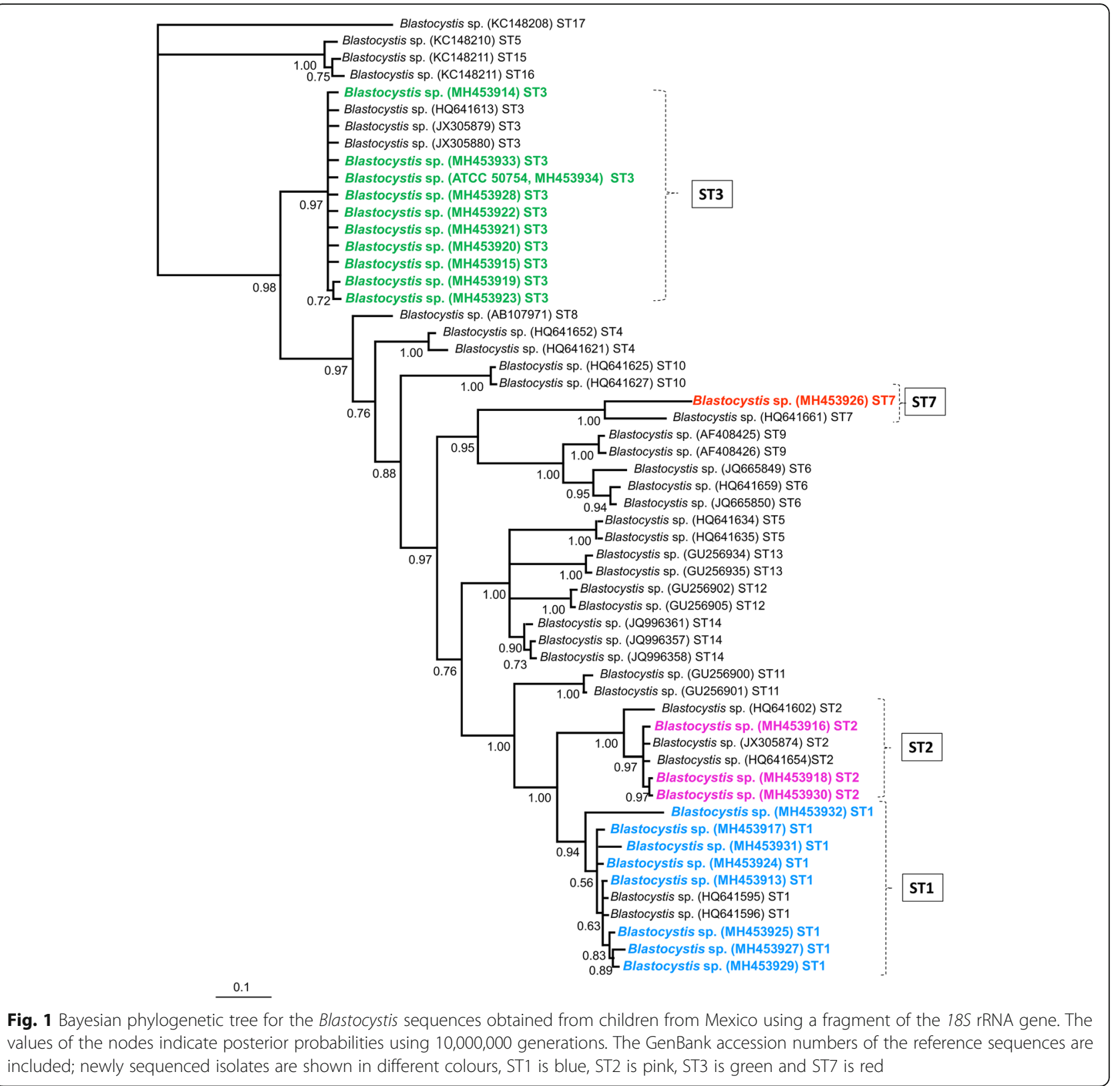

in this study for nucleotide diversity $(\pi)$ and haplotype polymorphism $(\theta)$ for the $18 S$ gene were in accordance with previous studies of genetic diversity in Blastocystis infections in children from other geographical regions of Mexico [41, 43]. Interestingly, the $\pi$ and $\theta$ values for ST1 or ST2 were almost 10-fold higher than those for ST3, indicating a high reduction of the variability within and among sequences in this subtype. This result is consistent with previous studies in which isolates of ST3 from patients with irritable bowel syndrome showed lower genetic variability than those from asymptomatic carriers [44]. A study focused on the genetic variability and host specificity of Blastocystis spp. in wild howler monkeys from two rainforest areas in the south-eastern region of Mexico reported that ST1 exhibits a generalist profile similar to a metapopulation, whereas ST2 existed as a set of local populations [5]. Another study aimed to determine the frequency and distribution of Blastocystis subtypes in free-ranging Macaca fascicularis in Thailand and showed that ST3 was the most common subtype detected (36\%), followed by ST2 and ST1 (24\% and $17 \%$, respectively). However, some new subtype alleles were also identified [45]. These reports suggest that the presence of different levels of cryptic host specificity in Blastocystis may modify the genetic population structure of this microorganism, including its levels of genetic 


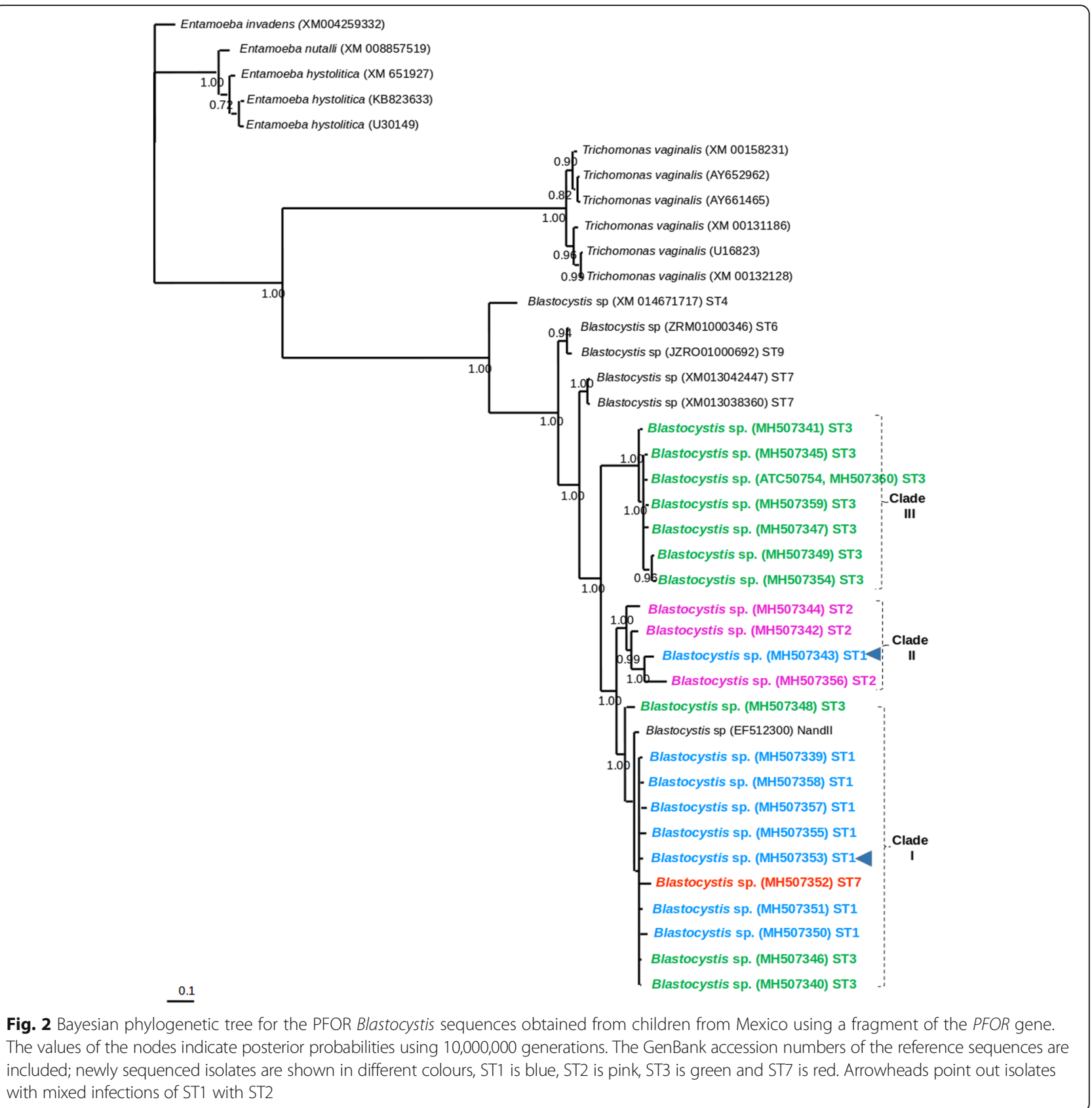

variability. Additionally, the negative values of Tajima's $D$ test suggest a recent expansion process or an effect of purifying selection in ST1-ST3 [39], strengthening the action of other evolutionary forces in the epidemiological landscape of Blastocystis. The mixed infections with ST1 and ST2 identified in two samples in the present study are in accordance with other studies reported mixed infections of ST1 with other STs (c.10\%) [46, 47].

Regarding the phylogenetic tree for PFOR, sequences that belonged to other parasites were grouped into separate clades as expected. The PFOR sequences that belonged to Blastocystis were grouped into three clades. In two of the clades, different STs were gathered without a predominant ST; only one clade grouped seven samples of ST3 and also included the ATCC-50754 strain (ST3). The presence of differences between the PFOR and $18 S$ trees is not surprising and is common when phylogenetic inferences drawn from different genes are compared [48]. Therefore, this initial analysis, although indicating that the PFOR gene locus used in the present study is not sensitive enough to differentiate subtypes, suggests that the phylogeny of PFOR may provide inferences about the function of the protein instead of the 
Table 2 Genetic polymorphism indexes between different Blastocystis sequences

\begin{tabular}{|c|c|c|c|c|c|c|}
\hline Marker & $\begin{array}{l}\text { No. of } \\
\text { sequences }\end{array}$ & $\mathrm{H}^{\mathrm{a}}$ & $\mathrm{Hd}^{\mathrm{b}}$ & $\pi^{c} \pm S D^{d}$ & $\theta^{e} \pm S D$ & $\begin{array}{l}\text { Tajima's D } \\
(P \text {-value })\end{array}$ \\
\hline \multicolumn{7}{|l|}{185 rDNA } \\
\hline ST1 & 10 & 6 & 0.867 & $0.0293 \pm 0.0157$ & $0.0470 \pm 0.0199$ & $-1.9031(\leq 0.05)$ \\
\hline ST2 & 6 & 5 & 0.933 & $0.0201 \pm 0.0109$ & $0.0258 \pm 0.0129$ & $-1.3898(\geq 0.10)$ \\
\hline ST3 & 13 & 8 & 0.894 & $0.0045 \pm 0.001$ & $0.0055 \pm 0.0028$ & $-0.6024(\geq 0.10)$ \\
\hline \multicolumn{7}{|l|}{ PFOR } \\
\hline Clade I & 10 & 8 & 0.956 & $0.0311 \pm 0.0117$ & $0.0457 \pm 0.0199$ & $-1.7406(\leq 0.05)$ \\
\hline Clade II & 4 & 4 & 1.000 & $0.0655 \pm 0.0137$ & $0.0635 \pm 0.0350$ & $-0.5006(\geq 0.10)$ \\
\hline Clade III & 6 & 5 & 0.933 & $0.0079 \pm 0.0027$ & $0.0098 \pm 0.0052$ & $-1.2217(\geq 0.10)$ \\
\hline
\end{tabular}

${ }^{\mathrm{a}} \mathrm{H}$, number of haplotypes

${ }^{\mathrm{b}} \mathrm{Hd}$, haplotype diversity

${ }^{c} \pi$, nucleotide diversity

${ }^{\mathrm{d}} \mathrm{SD}$, standard deviation

${ }^{e} \theta$, haplotype polymorphism

relationship of the group. On the other hand, it has been argued that in some genomes of intestinal pathogens [49], including Blastocystis [50], PFOR is a single-copy gene, and hence this marker may be subjected to different selection pressures, according to studies of multi- and single-copy genes [39]. In addition, the results obtained could have been influenced by other evolutionary processes, such as homoplasy [51], genetic hitchhiking [52] or simply the high conservation of the analysed PFOR fragment, which corresponds to a region inside the active site of the protein. To clarify these factors, complete sequencing of the PFOR gene should be performed. When comparing genetic resolution to the $18 S$ gene, future studies for of the PFOR gene and new genetic molecular markers must address mixed infections to avoid problematic clustering, such as the clustering of clades I and II observed in this study. $18 \mathrm{~S}$ gene analysis has shown that this marker is sensitive enough to resolve phylogenetic relationships, population differentiation events and cryptic infections in Blastocystis [41, 43, 53-55]. Finally, the knowledge of the genetic variation within and between populations can be applied to the epidemiology and the control of parasites because these biological features influence future evolutionary changes, genetic differentiation, and speciation in many pathogens $[5,40,41]$.

\section{Conclusions}

Although the fragment of the PFOR gene analysed in present study did not allow discrimination between Blastocystis STs, this marker grouped the samples in three strongly-supported clades, suggesting that PFOR may be under different selective pressures and evolutionary histories than the $18 \mathrm{~S}$ gene. Interestingly, ST3 sequences showed lower variability with probable purifying selection in both markers, meaning that evolutionary forces are driving differential processes among the Blastocystis STs. Finally, according to Poirier et al. [56], the controversial role of Blastocystis spp. as pathogens remains unclear. Thus, there is still a need to conduct epidemiological studies focused on distinguishing between strains within subtypes of this genus.

\section{Abbreviations \\ 185 rDNA: Small-subunit ribosomal RNA; ATCC: American Type Culture Collection; BSA: Bovine serum albumin; CoA: Coenzyme A; \\ Fd: Ferredoxin; Fe-S: Iron-Sulfur; H: Number of haplotypes; Hd: Haplotype diversity; IMIEM: Instituto Materno Infantil from the State of Mexico; PCR: Polymerase chain reaction; PFOR: Pyruvate:ferredoxin oxidoreductase enzyme; SD: Standard deviation; ST: Subtype; TPP: Thiamine pyrophosphate; $\theta$ : Haplotype polymorphism; $\pi$ : Nucleotide diversity}

\section{Acknowledgements}

The authors thank the support and assistance of authorities and staff at the Laboratory of Hospital para el Niño, IMIEM, especially to QFB. Maria de las Mercedes Rojas Moreno and TLC Esther Sanchez Rebollo. Patricia AlarconValdes is a Master's student from Facultad de Quimica, Universidad Autonoma del Estado de Mexico.

Funding

This research was sponsored by the grant number 168619 from the Consejo Nacional de Ciencia y Tecnologia (CONACYT), Mexico.

Availability of data and materials

All relevant data supporting the conclusions of this article are included within the article.

\section{Authors' contributions}

PA-V collected the samples and performed the coprological assays. PA-V, EL-E, NRG-A and MR-V performed the PCR, purification of amplicons and sequencing assays. GV, WAM-F and FM-H performed the genetic analysis. GV, JGS-B and PM formulated the idea. WAM-F and MR-V contributed with critical comments. PA-V obtained the authorisations. All authors read and approved the final manuscript.

\section{Ethics approval and consent to participate}

The Ethics and Research Committee of the Hospital para el Niño, IMIEM approved the study reference number 217D12101-300/091/2016.

Consent for publication

Not applicable. 


\section{Competing interests}

The authors declare that they have no competing interests.

\section{Publisher's Note}

Springer Nature remains neutral with regard to jurisdictional claims in published maps and institutional affiliations.

\section{Author details}

${ }^{1}$ Facultad de Quimica, Universidad Autonoma del Estado de Mexico (UAEMex), Paseo Colon esq. Paseo Tollocan, Toluca, Estado de Mexico, Mexico. ${ }^{2}$ Instituto de Ecologia, Universidad Nacional Autonoma de Mexico (UNAM), 04510, Ciudad de Mexico, Ciudad de Mexico, Mexico. ${ }^{3}$ Hospital General "Dr. Manuel Gea Gonzalez", Calzada de Tlalpan 4800, Ciudad de Mexico, 14080 Ciudad de Mexico, Mexico.

Received: 8 June 2018 Accepted: 10 October 2018 Published online: 29 October 2018

\section{References}

1. Derelle R, Lopez-Garcia P, Timpano H, Moreira D. A phylogenomic framework to study the diversity and evolution of stramenopiles (=heterokonts). Mol Biol Evol. 2016;33:2890-8.

2. Burki F. The eukaryotic tree of life from a global phylogenomic perspective. Cold Spring Harb Perspect Biol. 2014;6:a016147.

3. Worasilchai N, Permpalung N, Chindamporn A. High-resolution melting analysis. A novel approach for clade differentiation in Pythium insidiosum and pythiosis. Med Mycol. 2017. https://doi.org/10.1093/mmy/myx123.

4. Gentekaki E, Curtis BA, Stairs CW, Klimeš V, Eliaš M, Salas-Leiva DE, et al. Extreme genome diversity in the hyper-prevalent parasitic eukaryote Blastocystis. PLoS Biol. 2017;15:e2003769.

5. Villanueva-Garcia C, Gordillo-Chavez EJ, Lopez-Escamilla E, Rendon-Franco E, Muñoz-Garcia Cl, Gama L, et al. Clarifying the cryptic host specificity of Blastocystis spp. isolates from Alouatta palliata and A. pigra howler monkeys. PLoS One. 2017;12:e0169637.

6. Alfellani MA, Taner-Mulla D, Jacob AS, Imeede CA, Yoshikawa H, Stensvold $C R$, et al. Genetic diversity of Blastocystis in livestock and zoo animals. Protist. 2013;164:497-509.

7. Clark CG. Cryptic diversity in intestinal protists. Parasite. 2008;15:317-20.

8. Noël C, Dufernez F, Gerbod D, Edgcomb VP, Delgado-Viscogliosi P, Ho LC, et al. Molecular phylogenies of Blastocystis isolates from different hosts: implications for genetic diversity, identification of species, and zoonosis. J Clin Microbiol. 2005;43:348-55.

9. Turkeltaub JA, McCarty TR 3rd, Hotez PJ. The intestinal protozoa: emerging impact on global health and development. Curr Opin Gastroenterol. 2015; 31:38-44.

10. Jimenez-Gonzalez DE, Martinez-Flores WA, Reyes-Gordillo J, Ramirez-Miranda ME, Arroyo-Escalante S, Romero-Valdovinos $\mathrm{M}$, et al. Blastocystis infection is associated with irritable bowel syndrome in a Mexican patient population. Parasitol Res. 2012;110:1269-75.

11. Yakoob J, Jafri W, Beg MA, Abbas Z, Naz S, Islam M, et al. Irritable bowel syndrome: is it associated with genotypes of Blastocystis hominis. Parasitol Res. 2010;106:1033-8.

12. Scanlan PD. Blastocystis: past pitfalls and future perspectives. Trends Parasitol. 2012:28:327-34.

13. Stensvold CR, van der Giezen M. Associations between gut microbiota and common luminal intestinal parasites. Trends Parasitol. 2018. https://doi.org/ 10.1016/j.pt.2018.02.004

14. Ajjampur SS, Tan KS. Pathogenic mechanisms in Blastocystis spp.interpreting results from in vitro and in vivo studies. Parasitol Int. 2016;65: 772-9.

15. Alfellani MA, Stensvold CR, Vidal-Lapiedra A, Onuoha ES, Fagbenro-Beyioku AF, Clark CG. Variable geographic distribution of Blastocystis subtypes and its potential implications. Acta Trop. 2013;126:11-8.

16. Karkowska-Kuleta J, Kozik A. Moonlighting proteins as virulence factors of pathogenic fungi, parasitic protozoa and multicellular parasites. Mol Oral Microbiol. 2014;29:270-83.

17. Collingridge PW, Brown RW, Ginger ML. Moonlighting enzymes in parasitic protozoa. Parasitology. 2010;137:1467-75.

18. Chabriere E, Cavazza C, Contreras-Martel C, Fontecilla-Camps JC. Pyruvateferredoxin oxidoreductase. In: Encyclopedia of Inorganic and Bioinorganic
Chemistry. Hoboken: Wiley; 2011. http://onlinelibrary.wiley.com/doi/10.1002/ 9781119951438.eibc0647/abstract.

19. Eram MS, Oduaran E, Ma K. The bifunctional pyruvate decarboxylase/ pyruvate ferredoxin oxidoreductase from Thermococcus quaymasensis. Archaea. 2014;2014:349379.

20. Ragsdale SW. Pyruvate ferredoxin oxidoreductase and its radical intermediate. Chem Rev. 2003;103:2333-46.

21. Uyeda K, Rabinowitz JC. Pyruvate-ferredoxin oxidoreductase. 3. Purification and properties of the enzyme. J Biol Chem. 1971;246:3111-9.

22. Reeves RE, Warren LG, Susskind B, Lo HS. An energy-conserving pyruvate-toacetate pathway in Entamoeba histolytica. Pyruvate synthase and a new acetate thiokinase. J Biol Chem. 1977;252:726-31.

23. Williams K, Lowe PN, Leadlay PF. Purification and characterization of pyruvate: ferredoxin oxidoreductase from the anaerobic protozoon Trichomonas vaginalis. Biochem J. 1987:246:529-36.

24. Townson SM, Upcroft JA, Upcroft P. Characterisation and purification of pyruvate:ferredoxin oxidoreductase from Giardia duodenalis. Mol Biochem Parasitol. 1996;79:183-93.

25. Wawrzyniak I, Roussel M, Diogon M, Couloux A, Texier C, Tan KS, et al. Complete circular DNA in the mitochondria-like organelles of Blastocystis hominis. Int J Parasitol. 2008;38:1377-82.

26. Song HO. Influence of $120 \mathrm{kDa}$ pyruvate:ferredoxin oxidoreductase on pathogenicity of Trichomonas vaginalis. Korean J Parasitol. 2016:54:71-4.

27. Phillips BP, Zierdt CH. Blastocystis hominis: pathogenic potential in human patients and in gnotobiotes. Exp Parasitol. 1976;39:358-64.

28. Santin M, Gomez-Muñoz MT, Solano-Aguilar G, Fayer R. Development of a new PCR protocol to detect and subtype Blastocystis spp. from humans and animals. Parasitol Res. 2011:109:205-12.

29. Yoshikawa H, Abe N, Iwasawa M, Kitano S, Nagano I, Wu Z, et al. Genomic analysis of Blastocystis hominis strains isolated from two long-term health care facilities. J Clin Microbiol. 2000;38:1324-30.

30. Yoshikawa H, Wu Z, Nagano I, Takahashi Y. Molecular comparative studies among Blastocystis isolates obtained from humans and animals. J Parasitol. 2003;89:585-94.

31. Yoshikawa H, Wu Z, Kimata I, Iseki M, Ali IK, Hossain MB, et al. Polymerase chain reaction-based genotype classification among human Blastocystis hominis populations isolated from different countries. Parasitol Res. 2004;92:22-9.

32. Yan Y, Su S, Lai R, Liao H, Ye J, Li X, et al. Genetic variability of Blastocystis hominis isolates in China. Parasitol Res. 2006;99:597-601.

33. Li LH, Zhang XP, Lv S, Zhang L, Yoshikawa H, Wu Z, et al. Cross-sectional surveys and subtype classification of human Blastocystis isolates from four epidemiological settings in China. Parasitol Res. 2007;102:83-90.

34. Thompson JD, Higgins DG, Gibson TJ. CLUSTAL W: Improving the sensitivity of progressive multiple sequence alignment through sequence weighting, position-specific gap penalties and weight matrix choice. Nucleic Acids Res. 1994;22:4673-80.

35. Edgar RC. MUSCLE: Multiple sequence alignment with high accuracy and high throughput. Nucleic Acids Res. 2004;32:1792-7.

36. Kumar S, Stecher G, Tamura K. MEGA7: Molecular Evolutionary Genetics Analysis version 7.0 for bigger datasets. Mol Biol Evol. 2016;33:1870-4.

37. Ronquist F, Teslenko M, van der Mark P, Ayres DL, Darling A, Höhna S, et al. MrBayes 3.2: Efficient Bayesian phylogenetic inference and model choice across a large model space. Syst Biol. 2012:61:539-42.

38. Rozas J, Ferrer-Mata A, Sánchez-DelBarrio JC, Guirao-Rico S, Librado P, Ramos-Onsins SE, et al. DnaSP 6: DNA sequence polymorphism analysis of large datasets. Mol Biol Evol. 2017;34:3299-302.

39. Hartl DL, Clark AG. Principles of Population Genetics. Sunderland: Sinauer Associates, Inc. Publishers; 1997.

40. Poirier P, Meloni D, Nourrisson C, Wawrzyniak I, Viscogliosi E, Livrelli V, et al. Molecular subtyping of Blastocystis spp. using a new rDNA marker from the mitochondria-like organelle genome. Parasitology. 2014;141:670-81.

41. Villalobos G, Orozco-Mosqueda GE, Lopez-Perez M, Lopez-Escamilla E, Cordoba-Aguilar A, Rangel-Gamboa L, et al. Suitability of internal transcribed spacers (ITS) as markers for the population genetic structure of Blastocystis spp. Parasit Vectors. 2014;7:461

42. Stensvold CR, Alfellani M, Clark CG. Levels of genetic diversity vary dramatically between Blastocystis subtypes. Infect Genet Evol. 2012;12:263-73.

43. Villegas-Gomez I, Martinez-Hernandez F, Urrea-Quezada A, Gonzalez-Diaz M Durazo M, Hernandez J, et al. Comparison of the genetic variability of Blastocystis subtypes between human carriers from two contrasting climatic regions of Mexico. Infect Genet Evol. 2016;44:334-40. 
44. Vargas-Sanchez GB, Romero-Valdovinos M, Ramirez-Guerrero C, VargasHernandez I, Ramirez-Miranda ME, Martinez-Ocaña J, et al. Blastocystis isolates from patients with irritable bowel syndrome and from asymptomatic carriers exhibit similar parasitological loads, but significantly different generation times and genetic variability across multiple subtypes. PLoS One. 2015;10:e0124006.

45. Vaisusuk K, Saijuntha W, Sedlak S, Thanchomnang T, Pilap W, Suksavate W, et al. Blastocystis subtypes detected in long-tailed macaques in Thailand further evidence of cryptic host specificity. Acta Trop. 2018;184:78-82.

46. Pandey PK, Verma P, Marathe N, Shetty S, Bavdekar A, Patole MS, et al. Prevalence and subtype analysis of Blastocystis in healthy Indian individuals. Infect Genet Evol. 2015;31:296-9.

47. Valença Barbosa C, de Jesus Batista R, Pereira Igreja R, d'Avila Levy CM, Werneck de Macedo H, Carneiro Santos HL. Distribution of Blastocystis subtypes isolated from humans from an urban community in Rio de Janeiro, Brazil. Parasit Vectors. 2017;10:518.

48. Baum DA, Smith SD. Tree Thinking: An Introduction to Phylogenetic Biology. Greenwood Village, CO: Roberts \& Co.; 2013.

49. Rodriguez M, Hidalgo MA, Sanchez T, Orozco E. Cloning and characterization of the Entamoeba histolytica pyruvate:ferredoxin oxidoreductase gene. Mol Biochem Parasitol. 1996;78:273-7.

50. Wawrzyniak I, Courtine D, Osman M, Hubans-Pierlot C, Cian A, Nourrisson C, et al. Draft genome sequence of the intestinal parasite Blastocystis subtype 4-isolate WR1. Genom Data. 2015;4:22-3.

51. Sanmartin I, Meseguer AS. Extinction in phylogenetics and biogeography: from timetrees to patterns of biotic assemblage. Front Genet. 2016;7:35.

52. Barton NH. Genetic hitchhiking. Philos Trans R Soc Lond B Biol Sci. 2000;355: 1553-62.

53. Alfellani MA, Jacob AS, Perea NO, Krecek RC, Taner-Mulla D, Verweij JJ, et al. Diversity and distribution of Blastocystis sp. subtypes in non-human primates. Parasitology. 2013;140:966-71.

54. Chambouvet A, Gower DJ, Jirkủ M, Yabsley MJ, Davis AK, Leonard G, et al. Cryptic infection of a broad taxonomic and geographic diversity of tadpoles by Perkinsea protists. Proc Natl Acad Sci USA. 2015;112:E4743-51.

55. Stensvold CR, Alfellani MA, Nørskov-Lauritsen S, Prip K, Victory EL, Maddox C, et al. Subtype distribution of Blastocystis isolates from synanthropic and zoo animals and identification of a new subtype. Int J Parasitol. 2009:39:473-9.

56. Poirier $P$, Wawrzyniak I, Vivarès CP, Delbac F, El Alaoui H. New insights into Blastocystis spp.: a potential link with irritable bowel syndrome. PLoS Pathog. 2012;8:e1002545

Ready to submit your research? Choose BMC and benefit from:

- fast, convenient online submission

- thorough peer review by experienced researchers in your field

- rapid publication on acceptance

- support for research data, including large and complex data types

- gold Open Access which fosters wider collaboration and increased citations

- maximum visibility for your research: over $100 \mathrm{M}$ website views per year

At $\mathrm{BMC}$, research is always in progress.

Learn more biomedcentral.com/submissions 